\title{
EL REEMPLAZO DEL BENEFICIO DE PATIO EN LA MINERÍA PERUANA, 1850-1913¹
}

\author{
POR \\ CARLOS CONTRERAS 2 \\ Pontificia Universidad Católica del Perú, Lima
}

\begin{abstract}
Después de una vigencia de más de trescientos años, el método de amalgamación con azogue fue reemplazado en la minería peruana de la plata, en la década de 1890. Esta sustitución tuvo lugar cuando los principales productores mundiales empleaban desde hacía medio siglo otros métodos de beneficio. El retraso para el abandono del método de la amalgamación en el Perú tuvo que ver con el hecho de contar el país con una mina de mercurio, que, aunque paralizada, alimentó siempre esperanzas de reactivación, la carencia de capital para proceder a un cambio técnico de envergadura y la larga vigencia de una legislación que no fomentaba el despegue de una minería de gran escala. Cuando, después de 1885, algunas de estas condiciones cambiaron, hubo una batalla por el cambio técnico, donde se enfrentaron las propuestas de la Escuela de Ingenieros, defensora de la lixiviación, y las empresas extranjeras, más amigas de la técnica de la fundición. La culminación de los ferrocarriles, en los primeros años del siglo XX, ayudó a la victoria de la segunda propuesta. Si bien ésta era más eficiente técnicamente, guardaba menos efectos redistributivos en la economía regional y nacional.
\end{abstract}

Durante el siglo XIX la minería de la plata se estancó en el Perú. «El virreinato del oro y la plata es reemplazado por la república del guano y el salitre», fue el resumen de Carlos Jiménez en su reseña histórica de la minería peruana al cumplirse el centenario de la victoria de Ayacucho $^{3}$. En las últimas décadas del

SIGLA UTILIZADA:

BMIC: Boletín de Minas, Industria y Construcciones.

1 Versión revisada de la ponencia presentada en la V Reunión de Historiadores de la Minería Latinoamericana. San Luis Potosí (México): 14 al 18 de julio de 1997. Agradezco los comentarios de Tristan Platt y Héctor Noejovich sobre la primera versión de este trabajo.

2 El autor es profesor en el Departamento de Economía de la Pontificia Universidad Católica del Perú.

3 Carlos JiMÉNEZ, «Reseña histórica de la minería en el Perú». En Ministerio de Fomento, Sintesis de la minería peruana en el centenario de Ayacucho, Lima, 1924, p.46. 
período colonial el Perú producía algo más de cien toneladas anuales de plata y un 13 por ciento de la producción mundial, mientras que en los mediados del siglo XIX producía sólo unas setenta toneladas anuales y un 8 por ciento del total mundial ${ }^{4}$. Meditando acerca de este retroceso, el geógrafo italiano Antonio Raimondi culpó, en un texto escrito en 1861, a la política del Estado independiente:

«Al ver los /asientos/ minerales, casi completamente abandonados, es imposible creer que todos se hayan agotado á un tiempo; y refleccionando, que casi todos se han paralizado después de la independencia, es preciso creer, que los gobiernos que se sucedieron después de esta época descuidaron mucho el ramo de minería, .... ${ }^{5}$.

El desinterés del gobierno republicano, puesto aún más de relieve frente a la activa política prominera del Estado colonial, vino a significar que la dotación de capital, mano de obra y renovación técnica, sería en adelante un asunto del que deberían ocuparse sólos los mineros. Consecuencia lógica de esta «liberalización», en un escenario carente de un mercado organizado capaz de reemplazar la acción estatal, fue la postración de la actividad en lo que era su principal renglón: la producción de plata (y la completa desaparición de su segundo: la producción de mercurio). Uno de los signos más evidentes de la involución de la minería argentífera fue el estancamiento técnico, padecido ya desde el fracaso de la expedición del Barón de Nordenflicht entre 1790 y 1810.

Cuando hablamos de cambio técnico debemos concordar que en la minería la fase clave residía en el sector metalúrgico; es decir, en el beneficio o tratamiento de los minerales para su conversión en metal puro. Es este sector el que demandaba producción de la fase extractiva, orientando en consecuencia (más que siguiendo) cambios técnicos también en él; se constituye, pues, en el motor o locomotora del cambio técnico en la minería.

En el Perú, como en otros países americanos, la tecnología de beneficio de la minería de la plata durante el régimen colonial estuvo dominada por el método de amalgamación con azogue ideado por Bartolomé de Medina en México en el siglo XVI y conocido también como el «método de patio». La virtud principal de este método era realizar la separación de la plata «en frío»; es decir, sin demandar combustible ${ }^{6}$. En el antiguo país de los incas se trató de un predominio todavía mayor, en la medida que el procedimiento por fundición, que por entonces

4 Véase John FISHER, Minas y mineros en el Perú colonial, 1776-1824, Lima, IEP, 1977 y Jiménez [3], p.50.

5 RAIMONDI, El Perú, t.IV, p.514, Lima, Sociedad Geográfica de Lima, 4 ts., 1902.

6 Para conseguir la mejora de la amalgamación, debía usarse, sin embargo, fuego en diversos momentos, por lo que el método no era totalmente en frío; simplemente demandaba menos combustible que el método alternativo de la fundición.

R. I., $1999, \mathrm{n}^{\circ} 216$ 
era el método alternativo, no parecía adaptarse al tipo de minerales nativos, además de padecerse de la escasez de combustible, ingrediente básico en el ${ }^{7}$. El método de patio estuvo vigente en el Perú por más de tres siglos: entre la década de 1570 y la de 1890 . Su reemplazo fue relativamente tardío, puesto que en México fue abandonado varias décadas antes y en las postrimerías del siglo XIX ya no era utilizado en ninguna nación que fuera una importante productora de plata.

Siendo el mercurio el insumo fundamental del método de patio, y hallándose paralizadas las minas de este metal en Huancavelica desde la abolición de la mita en 1812, cualquiera habría esperado un cambio técnico en la metalurgia argentífera más precoz, puesto que el precio del mercurio rápidamente se triplicó después de la independencia ${ }^{8}$. Pero en vez de ello, los peruanos empeñaron esfuerzos en conseguir el reflotamiento de la célebre mina americana de mercurio, fracasando una y otra vez en el intento'.

A pesar de que la tecnología alternativa al uso del mercurio estuvo ya disponible desde mediados de la centuria, debieron pasar varias décadas para que los métodos nuevos llegaran a implantarse masivamente en el país. En este artículo queremos estudiar el proceso que siguió el reemplazo del método de patio en la minería peruana, las razones por las cuales no se produjo antes, y los intereses enfrentados en la decisión del nuevo método de beneficio a adoptar. Este estudio nos servirá, asimismo, para dar a conocer algunas características relevantes de la minería de la plata en la segunda mitad del siglo XIX; un período hasta hoy descuidado por la investigación histórica ${ }^{10}$.

7 El predominio del método de patio obedeció además a la existencia de la mina de Huancavelica, que dotaba al virreinato peruano de una importante autosuficiencia en cuanto a los insumos para tal método. Los mineros indígenas siguieron usando, sin embargo, el método de la «huayra» (un horno sencillo avivado por el viento), que resultaba provechoso para minerales de ley muy alta. Pero se trataba por lo general de producción clandestina. Como combustible apelaron al uso de la «taquia»; estiércol de llamas u ovejas.

8 El quintal de mercurio pasó de un precio de 50 pesos a finales de la colonia, a uno de 80 a 90 pesos alrededor de 1826-1828. A partir del monopolio de la Casa Rotschild sobre el ingrediente, su precio sobrepasó los 150 pesos, amansándose recién después de 1850 , una vez descubiertas las minas de Nuevo Almadén, en California. Véase Mariano de RIVERO y UsTARIZ, «Memoria sobre el rico mineral de Pasco» (1828), p.218, en Colección de Memorias Científicas, Agrícolas e Industriales, Bruselas, 1858,2 ts.

9 En 1836 el empresario Domingo Olavegoya realizó un intento, fallido, de rehabilitación. Otros fracasos fueron, en 1839, de la «Compañía Metalúrgica»; en 1843, de la «Sociedad Huancavelicana»; en 1846 de «Flores y Compañía»; y en 1866, de «Basadre y Compañía» (v. Carlos JIMÉNEZ [3], p.48). Urge un estudio que explique el fracaso de estos proyectos.

10 Para la primera mitad del siglo XIX contamos en cambio con el documentado trabajo de José DeustuA, La minería peruana y la iniciación de la república, 1820-1840, Lima, IEP, 1986. 


\section{LA PRODUCCION DE PLATA EN LA SEGUNDA MITAD DEL SIGLO XIX}

Las cifras de producción de plata para esta época no han sido reconstruidas aún satisfactoriamente. La estadística oficial comenzó en 1903, de modo que para el siglo XIX contamos sólo con referencias aisladas y algunas estimaciones provisionales ${ }^{11}$. Sobre la base de ellas podemos establecer el siguiente cuadro de la producción de plata durante el siglo XIX por quinquenios:

\section{CUADRO 1}

Producción de plata en el Perú, 1801-1919 por quinquenios (en toneladas anuales)

\begin{tabular}{lcc}
\hline Períodos & Prom. Anual & Prom. Anual según Deustua \\
\hline $1801-1805$ & 120 & \\
$1806-1810$ & 105 & \\
$1811-1815$ & 94 & 20 \\
$1816-1820$ & 91 & 53 \\
$1821-1825$ & 35 & 77 \\
$1826-1830$ & 84 & 92 \\
$1831-1835$ & 114 & 111 \\
$1836-1840$ & 68 & 88 \\
$1841-1845$ & 117 & \\
$1846-1850$ & 91 & \\
$1851-1855$ & 77 & \\
$1856-1860$ & 66 & \\
$1861-1865$ & 75 & \\
$1866-1870$ & 85 & \\
$1871-1875$ & 70 & \\
$1876-1880$ & 58 & \\
$1880-1889$ & 68 & \\
$1890-1894$ & 89 & \\
$1895-1899$ & 136 & \\
$1900-1904$ & 193 & \\
$1905-1909$ & 207 & \\
$1910-1914$ & 290 & \\
$1915-1919$ & 315 & \\
\hline
\end{tabular}

11 Hasta 1820 las cifras ofrecidas por FISHER [4] y DEUSTUA [10] parecen muy confiables. El período más oscuro es el corrido entre 1821 y más o menos 1885 . Para él hemos usado las cifras de Carlos JIMÉNEZ ([3], p.50), quien declara haber hecho en 1921 «.. una prolija investigación al respecto, compulsando y coordinando las apreciaciones parciales de Humboldt, Rivero, Paz Soldán, Tschudi, Soetber y otros, con las estadísticas de la Casa de Moneda, algunos informes consulares y otros documentos que eran todo lo posible de obtener, llegando a las cifras que damos ..».

R. I., 1999, n. $^{\circ} 216$ 


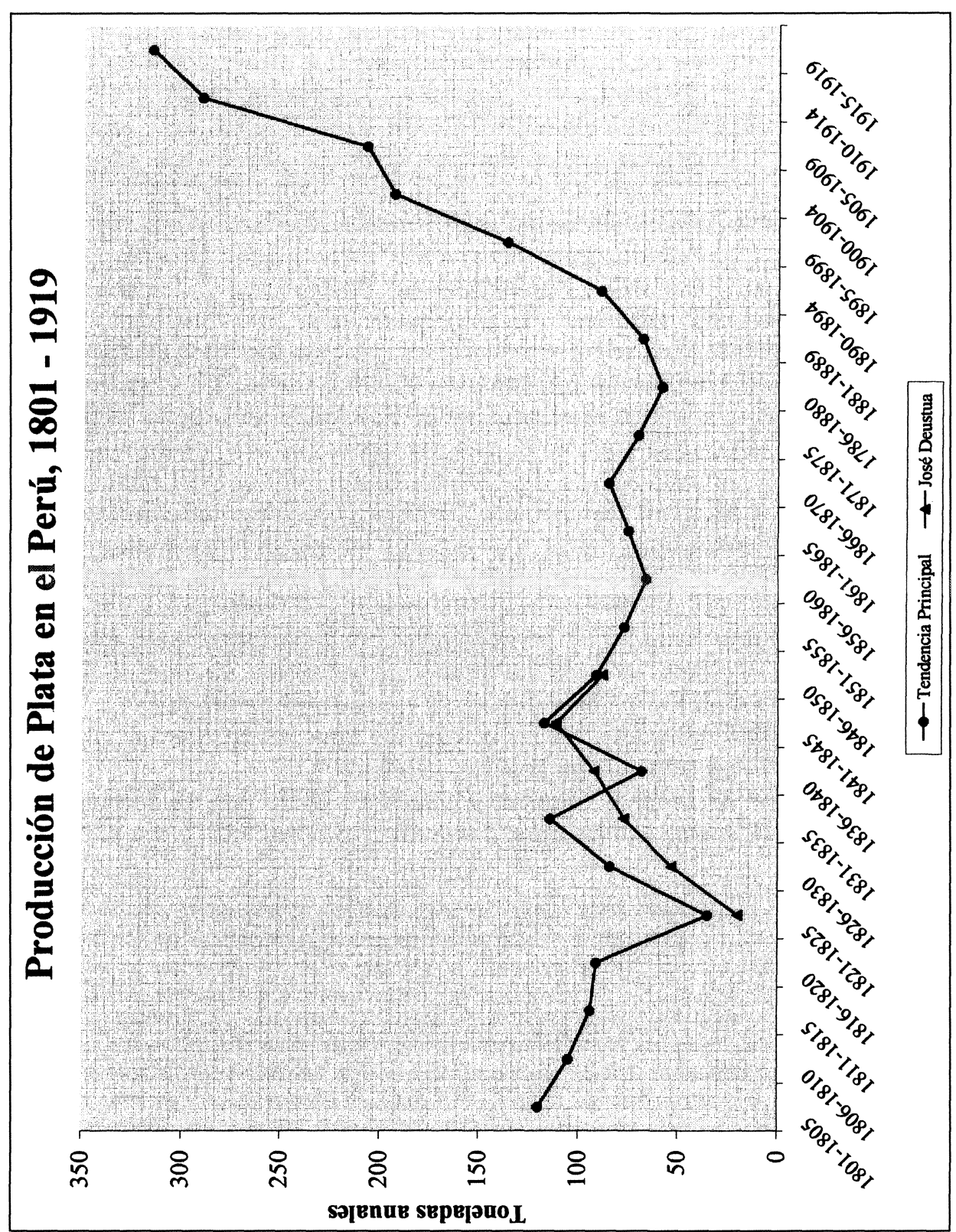

Fuente: Para el período 1801-1820: Deustua. La minería peruana, pp. 36-37; para 1821-1880: JIMÉNEZ, «Reseña histórica», p.50 (Deustua, La minería peruana, p.37 para las cifras de la segunda columna, quien trabajó sobre la base de una proyección a partir de las cifras de Cerro de Pasco); para 1880-1904: THORP-BERTRAM, Perú 1890-1977, p.109; de 1905 en adelante: Anuario de la minería peruana, 1933. 
El gráfico muestra para la segunda mitad del siglo XIX una situación de estancamiento y depresión de la producción de plata. La recuperación en torno a 1840 tuvo que ver con la conclusión del socavón desaguador de Quiulacocha, en Cerro de Pasco, y fue solamente pasajera. Desde el lustro 1846-1850, hasta el de 1890-1894 el país no llegó al número de cien toneladas anuales, que fue el promedio de finales de la colonia. Después de la guerra con Chile (1879-1883) se aprecia, no obstante, una recuperación más o menos rápida, al punto que al cerrarse la centuria el promedio anual rondaba las 150 toneladas. Durante los años de la primera Guerra Mundial el Perú superó por fin el record de los tiempos de mayor auge minero del virreinato, de aproximadamente 300 toneladas anuales, aunque por entonces la plata ya no representaba su renglón minero más importante.

Los testimonios cualitativos retratan con sombríos tonos dicho estancamiento. Tal vez el más sistemático es el de Antonio Raimondi, un experto italiano en mineralogía y botánica que vivió en el país por cuatro décadas, realizando diversos estudios y viajes por encargo del Estado. Entre 1860 y 1880 recorrió casi todos los asientos mineros, consignando penosos panoramas del estado de las labores: minas abandonadas, donde sólo algunos indígenas «busconeros» entraban esporádicamente a sacar algún mineral; ingenios paralizados, haciendas minerales en ruinas ${ }^{12}$. Tal vez de aquí nació su imagen del Perú como un mendigo sentado en un banco de oro, que corrientemente se le atribuye. Más expresivo aún fue Héctor Davelouis, un profesor francés de química y director de la Casa de Moneda de Lima en los mediados de siglo, quien llegó a exclamar: «... somos todos como Tántalo, ahogados en un océano de riquezas de que no podemos aprovechar, y cuyo aspecto aumenta nuestro suplicio» ${ }^{13}$.

La Estadística de Manuel Atanasio Fuentes de 1878, nos da a conocer la existencia de 1612 minas activas para dicho año; de ellas, 937 (o sea el 58 por

12 El más importante asiento de la región del norte, Hualgayoc, le mereció este comentario: «Este riquísimo mineral, que en los últimos 30 años del siglo pasado produjo más de 32 millones de pesos, se halla actualmente casi en total abandono; siendo muy pocas las minas que se trabajan en el día.» (RAIMONDI [5] t.IV, p.513). Al pasar por otros lugares, reseñó que «el célebre mineral de Castrovirreyna se haya en el día casi enteramente olvidado. Las ricas minas de Huantajaya y Santa Rosa, en la provincia de Tarapacá, han sido completamente abandonadas durante mucho tiempo, y sólo en este momento parece que quieren salir de su largo letargo, habiéndose formado una compañía para trabajarlas. Del tan ponderado mineral de azogue de Huancavelica solamente nos han quedado sus espaciosos y largos socavones, como un monumento histórico del estado en que se hallaba la minería en el Perú al principio de este siglo. En la quebrada que baja de la cordillera de Piedra Parada, cerca de Yauli, se notan las ruinas de 8 haciendas minerales. El mismo mineral del Cerro de Pasco se sostiene vacilante como en víspera de morir. Lo mismo puede decirse de Salpo, en la provincia de Huamachuco, ...» (id., p.514). En San Juan de Lucanas, al sur de Ayacucho, la situación era similar: «No hace todavía mucho tiempo que vivían en San Juan buen número de familias decentes formando algo de sociedad; pero ahora ésta tiende a disminuir (...) pues todo el pueblo está condenado á quedar en ruinas.» (id., p. 46).

13 Héctor DAveloUIS, Informe que el que suscribe eleva a la consideración de los Poderes Legislativo y Ejecutivo, sobre el estado actual de la Minería en el Perú, Lima, 1862, p. 22.

R. I., $1999, \mathrm{n}^{\circ} 216$ 
ciento) eran trabajadas por particulares, 674 (42 por ciento) por «empresas» y una por el Estado. Las «empresas» eran consideradas las compañías formadas por «sociedades anónimas» y ya mostraban un importante desarrollo en ese momento. Asimismo nos demuestra que la minería metálica dominante seguía siendo la de la plata, como lo manifiesta el siguiente cuadro:

\section{CUADRO 2}

Número de minas de acuerdo al mineral explotado en 1878

\begin{tabular}{lcc}
\hline & Nro. minas & $\%$ \\
\hline Plata & 870 & 54 \\
Carbón & 167 & 10 \\
Cobre & 118 & 7 \\
Petróleo & 53 & 3 \\
Plata y oro & 29 & 2 \\
Plata y cobre & 28 & 2 \\
Otros & 347 & 22 \\
\hline Total & 1612 & 100 \\
\hline
\end{tabular}

Fuente: Manuel A. Fuentes, Estadística de las Minas de la República del Perú en 1878. Lima, 1879.

La misma Estadística consigna un número de 5071 operarios mineros, aunque admite que la cifra es incompleta, puesto que se careció de datos para tres departamentos que no enviaron información (en el caso de Puno sorprende, de otro lado, tan bajo número de trabajadores); por lo que podríamos estimar un número aproximado de 5500 trabajadores en el Perú de 1878, con un promedio de apenas 3.4 operarios por mina en labor. Si comparamos este número con el de la Estadística de 1799 publicada por John Fisher, que arrojó 13.3 operarios por mina productiva, y un total de casi nueve mil trabajadores, puede comprobarse el estado desfalleciente del sector en vísperas de la guerra con Chile ${ }^{14}$.

Pero la Estadística de 1878, permite además apreciar que en medio de semejante postración había operado un importante cambio en la geografía de la producción: ya no eran Cerro de Pasco y Hualgayoc los centros que, como a finales de la colonia, dominaban unas cuatro quintas partes de la producción de plata. El cuadro con la distribución del número de operarios por departamento es liderado por Ancash, y muestra al de La Libertad, en una significativa tercera posición

14 John FISHER [4], p.197. Aún tendríamos que tomar en cuenta que en la época que Fuentes levantó su estadística, había obrado cierta recuperación de la minería, en virtud de la depreciación del papel moneda con respecto al sol de plata, que aumentaba las ganancias de los mineros. 
(Cerro de Pasco se ubicaba en el departamento de Junín, mientras Hualgayoc, en el de Cajamarca). Huancavelica, por su parte, había dejado de ser una región minera principal.

\section{CUADRO 3}

Distribución de los operarios mineros por departamentos en 1878

\begin{tabular}{lcc}
\hline Departamentos ${ }^{15}$ & Operarios & Porciento \\
\hline Ancash & 1572 & 31 \\
Junín & 1412 & 28 \\
La Libertad & 952 & 19 \\
Cajamarca & 554 & 11 \\
Arequipa & 180 & 4 \\
Huancavelica & 161 & 3 \\
Lima & 149 & 3 \\
Apurímac & 58 & 1 \\
Cuzco & 28 & 1 \\
Puno & 5 & 0 \\
- Total & 5071 & 101 (por el redondeo) \\
\hline
\end{tabular}

En el departamento de Ancash se diseminaban minas en Pallasca, Huaylas y Huari; en La Libertad existían los yacimientos de Salpo, Quiruvilca y otros más bien auríferos en la provincia de Pataz. En la propia región central la importancia de Cerro de Pasco era ahora atemperada por centros como Yauli, Oyón y Morococha.

La situación decadente de la minería era, naturalmente, el resultado de escasos márgenes de ganancia. Usando los datos de los viajeros Herndon y Gibbon y del ingeniero Hilario Parra, Shane Hunt estableció hace algunos años que los beneficios netos de los mineros de Cerro de Pasco cayeron hasta volverse negativos; entre 1851 y 1875 pasaron del $7.5 \%$ al $-11 \%{ }^{16}$. Otras fuentes confirman esta tendencia. De acuerdo a Manuel A. Fuentes, el año 1877 los costos de la industria minera de Cerro de Pasco acumularon un total de 3.970,318 millones de soles, mientras la producción fue de 257,130 marcos. Solamente para recuperar lo invertido, el precio del marco tendría que haber sido de 15.44 soles, pero el marco no se pagaba en la plaza a más de nueve soles, de modo que el resultado

\footnotetext{
15 Faltaron datos de Ayacucho, Piura y Tacna.

16 Shane HUNT, «Guano y crecimiento en el Perú del siglo XIX», HISLA No. IV, Lima, 1984, p.42.

R. I., $1999, \mathrm{n}^{\circ} 216$
} 
tenía que ser una pérdida neta ${ }^{17}$. En 1879 Mauricio du Chatenet, profesor de la Escuela de Minas, realizó una nueva estimación, cuya conclusión era la pérdida de un 26 por ciento de lo invertido ${ }^{18}$. Una circunstancia fortuita aliviaba, sin embargo, a los mineros durante esos años: la necesidad del Estado de pagar la expropiación de las oficinas salitreras estatizadas por el gobierno peruano en 1875, había llevado a la difusión de un papel moneda depreciado hasta en un $60 \%$ respecto del sol de plata. El minero podía pagar muchos de sus gastos con estos billetes y aprovechar la diferencia ${ }^{19}$.

Otros elementos que afectaban la producción minera y que venían a constituir el «entorno empresarial» del sector, eran el estado de las comunicaciones, el número de trabajadores, la legislación, la política de impuestos y la disponibilidad de crédito. Con la única salvedad de los impuestos, todos resultaban factores que no favorecían el desarrollo minero. La superficie, ya accidentada, del territorio careció de medios modernos de comunicación hasta casi el final del siglo. En 1862 Héctor Davelouis apuntó, buscando retratar la falta de comunicaciones: "¿Qué decir, cuando una carga de carbón de piedra de diez arrobas, a 20 ó 30 leguas de Lima, se paga mucho más que una tonelada de Europa?» ${ }^{20}$. Las líneas férras empezaron a abrirse en 1868, pero por una inexplicable razón (probablemente de orden político) se comenzó por cubrir rutas pastoriles, como la de Mollendo-Juliaca, antes que las demandadas por la actividad minera. Cuando en 1879 estalló la guerra con Chile, apenas se había cubierto una tercera parte del ferrocarril de Lima a Cerro de Pasco ${ }^{21}$. La dependencia del transporte animal encareció el abastecimiento de insumos de todo tipo, pero especialmente de aquellos como la sal, las maderas o los instrumentos de fierro; así como de la propia mano de obra. Una de las razones por las que el viajero alemán Hugo Zöller, quien estuvo en el Perú tras el final de la guerra del Pacífico, se mostró escéptico sobre las posibilidades de recuperación de la economía del país, fue por el «difícil acceso» que padecían los asientos mineros, que debían ser la base de la misma $^{22}$.

Los problemas para el reclutamiento de trabajadores los hemos descrito ya en otro trabajo; resultaba muy difícil para las empresas asegurarse una mano de obra constante, y más aún, calificada, con la consecuencia de enormes costos y fre-

${ }_{17}$ Manual A. FuENTES, Estadística de las Minas de la República del Perú en 1878, Lima, 1879 , p. 215.

18 Mauricio DU CHATENET, «Estado actual de la industria minera en el Cerro de Pasco», Anales de la Escuela de Construcciones Civiles y de Minas, núm.1, Lima, 1880, p.80.

19 Du Chatenet, [18]

${ }^{20}$ Héctor DaveluoIs [13], p.23.

21 Esta línea recién se concluyó en 1904. Véase nuestro trabajo «Mineros, arrieros y ferrocarril en Cerro de Pasco, 1870-1904», HISLA, núm. IV, Lima, 1984.

22 Estuardo NúÑEZ (ed.), Viajeros alemanes en el Perú, Lima, Biblioteca Nacional, 1969, p. 137. 
cuentes pérdidas en este rubro ${ }^{23}$. El capital, por su parte, dispuso hasta la guerra, de lugares de colocación mucho más rentables y seguros que el sector minero. El auge del guano y luego el del salitre crearon una suerte de «enfermedad holandesa» durante el tercer cuarto de siglo. El propio negocio de exportación del guano, así como el comercio de importación y los préstamos al Estado con altos intereses se convirtieron en destinos del dinero mucho más atractivos y seguros que la inversión en minería ${ }^{24}$. Sobre los «capitalistas», Du Chatenet comentó en 1879, que: «.. se han dejado seducir por el cebo de las fáciles especulaciones, cuyo vasto campo les estuvo abierto durante varios años.», desistiendo de invertir en minería ${ }^{25}$.

La legislación heredada de la colonia permaneció inalterada hasta 1877 y no fue reemplazada integralmente hasta el código de 1900 (que empezó a regir el primero de enero de 1901). Durante gran parte del siglo XIX rigieron, pues, las Ordenanzas instauradas en 1786, que resultaron de una adaptación de las implantadas en México tres años antes, por lo que eran conocidas como las «Orde-

23 Véase nuestro trabajo: CONTRERAS, «Minería y mano de obra en el Perú del siglo XIX.», Siglo XIX núm. 8, Monterrey, 1989, pp. 9-50. El profesor Davelouis, antes citado, además de quejarse de la nula calificación de los indígenas para las labores, culpó, como tantos otros, a la abolición de la contribución de indígenas y la profusión de las festividades lugareñas de la falta de trabajadores para la minería. Merece transcribirse esta larga cita: «... los obreros indígenas son de tal inferioridad que me falta expresión para caracterizarla (...) Prefieren vivir como los cuadrúpedos y estar vestidos como los más asquerosos limosneros, ...» «No digo que se debe restablecer el trabajo obligatorio; pero digo que antes de la supresión de la contribución indígena, los indios trabajaban, y hoy que está suprimida no lo quieren hacer. Podría citar numerosos ejemplos, pero manifestaré uno que me es personal, á pesar de la amargura de que este recuerdo llena mi corazón. En el mes de mayo de 1860 , violentamente arrancado de mis estudios sobre la metalurgia de la plata, fui obligado, para sostener mi numerosa familia, á admitir las vivas solicitaciones que me hacía un minero de la provincia de Chota. Fui a esa provincia. Los metales eran favorables, todos. Los materiales superiores y abundantes. Fracasó la empresa, después de los más constantes esfuerzos, enteramente arruinada por la infamia de los obreros. Estos individuos, según la costumbre del lugar, no ganaban mas que un real y la comida; puse la tarea a dos reales, con una comida mas abundante y saludable, prodigué los remedios traídos para mi uso, estaban tratados como los hijos de la hacienda. La primera autoridad del departamento desplegó el mas laudable empeño y nada se consiguió. El lunes en lugar de treinta hombres, parecían cinco, el martes diez y era muy raro cuando se conseguía el número necesario, y todavía apenas uno ó dos días á la semana. Para conseguir la piedra de cal, de que las operaciones metalúrgicas necesitaban 50 arrobas, mil y mil trabajos costaron 12 arrobas en dos meses. Desesperado, arruinado, he preferido abandonar el capital invertido, mas bien que aumentar el perjuicio con una lucha sin esperanza. El menor pretexto es suficiente á estos hombres para abandonar el trabajo. Las innumerables fiestas religiosas, y que no tienen de tal sino el apellido, son también otro obstáculo á la regularidad del trabajo (...) Algún día una investigación estadística sobre el influjo de las fiestas, manifestará que las tres cuartas partes de los crímenes son debidos á las jaranas que fomentan las fiestas.» DAVELUOIS [13] , pp. 21-22.

24 Véase sobre ello: Heraclio BonILLA, Guano y burguesía en el Perú, Lima, IEP, 1974, como también Alfonso QuIROZ, Domestic and Foreign Finance in Modern Peru, 1850-1950, Financial Visions of Development, Pittsburgh, Universidad de Pittsburgh, 1993.

${ }^{25}$ Du CHATENET [18], p. 13.

R. I., 1999, $\mathrm{n}^{\circ} 216$ 
nanzas de México». En 1826 habían comenzado los intentos de reforma, mediante la formación de una comisión encargada de preparar un proyecto de ordenanzas. Fue la primera de muchas comisiones que, o no llegaron a cumplir su tarea, o la misma quedó empantanada en las cenagosas aguas del Congreso ${ }^{26}$.

La ley de 1877 fue preparada por Eduardo de Habich, fundador de la Escuela de Ingenieros, y Antonio Raimondi, inspirándose en los «Decretos Bases» de la revolución española de 1868. Aun cuando no significó un cambio completo de las Ordenanzas de México, introdujo modificaciones importantes. Entre ellas: permitir la propiedad de minas a extranjeros, abrir un Padrón de pertenencias mineras unificado y reemplazar la vigencia de los «denuncios» en mérito a que estuviesen «en labor», por el pago de una contribución de minas ${ }^{27}$. La ley de 1877 fue pensada como «las bases» de un futuro código minero, pero el torbellino de la guerra de 1879 truncó el proyecto, por lo que las Ordenanzas de México siguieron en vigor para los demás aspectos. En 1888 se reiniciaron los esfuerzos, nombrándose una comisión que presentó ese mismo año su trabajo. El ejecutivo elevó el proyecto al congreso, pero éste no decidió nada hasta que acabó el siglo. El Boletín de Minas, Industria y Construcciones de 1893, señalaba quejumbrosamente que la minería se hallaba regida en consecuencia por una multitud de ordenamientos, lo que «se presta evidentemente á toda clase de interpretaciones y enredos.» (p. 43).

Tal era el panorama de la minería en vísperas de su gran modernización. Sin capital, sin mano de obra, sin legislación apropiada respecto de la propiedad (aun rescatando la mejora de 1877), la proliferación de yacimientos mineros a lo largo y ancho de la cadena montañosa de los Andes, debía efectivamente representar para nosotros algo así como el suplicio de Tántalo. Centrémonos ahora en una cuestión técnica: los métodos de beneficio de la plata vigentes en la segunda mitad del siglo.

\section{EL BENEFICIO DE LA PLATA ENTRE 1850 Y 1880}

¿Cuáles eran los métodos de beneficio usados en el Perú a mediados de la centuria? Señalamos este momento, porque fue durante el mismo que en el mundo se realizó una gran innovación en la materia. Hasta entonces la tecnología disponible para la depuración de la plata se reducía a la fundición, y la amalgamación, sea ésta por el método de Medina en patios o buitrones, o por el europeo, en barriles rotatorios. La fundición descansaba en el uso de hornos —que fueron

\footnotetext{
26 Véase Alfredo Solf y Muro, «La legislación minera en el Perú», Síntesis de la minería peruana en el centenario de Ayacucho, Lima, Ministerio de Fomento, 1924, vol. I, pp. 245-280.

27 Sobre la importancia de la Ley de 1877, véase Mario SAMAMÉ BoGGIO, El Perú minero, t.I, Historia, pp. 126-127.
} 
perfeccionándose y adquiriendo mayores dimensiones a lo largo del siglo- y era apta para minerales con mucho plomo y donde el acceso al combustible fuera fácil y económico. La amalgamación se basaba en el uso de mercurio y variaba de acuerdo al recipiente donde se practicara la mezcla: patios o «circos» de piedra, donde se usaban caballos para mezclar la masa; tinas de madera, cobre o fierro, o barriles, de los mismos materiales. En el caso de las tinas y barriles la mezcla se agitaba mediante procedimientos mecánicos: bombas, ingenios o turbinas. Las tinas se usaban sobre todo en los Estados Unidos («pans americanos»), mientras los barriles (método de Freyberg) eran más comunes en Europa y México. En todos los casos los minerales debían ser previamente preparados, lo que incluía acciones de molienda y calcinación, de modo que los hornos eran indispensables en cualquiera de los procedimientos utilizados.

Desde el punto de vista de la empresa minera el mejor método era el que lograba sacar la mayor cantidad de plata de los minerales, al menor costo. La fundición, por ejemplo, no conseguía recuperar más de un $60 \%$ de la plata contenida, pero las circunstancias locales podían hacer que el ahorro de gastos en la operación compensara la pérdida de plata. El incremento del precio del mercurio en el mercado mundial durante las décadas de 1830 y 1840 llevó a la búsqueda de métodos que prescindieran de este ingrediente. Nació así la lixiviación.

El beneficio por lixiviación más antiguo nació en Alemania en 1849 (método de Augustín) y consistía en conseguir, primero, la formación de cloruro de plata a partir de los minerales pulverizados, en una mezcla con sal y usando hornos de calcinación; luego, el cloruro era disuelto mediante hiposulfito de sodio en unas tinas, para finalmente conseguir la «precipitación» (paso al estado sólido) de la plata mediante planchas de cobre. No se perdía mercurio, sino sólo unas soluciones químicas de bajo costo y que podían ser preparadas en cada establecimiento metalúrgico, a partir de ciertos insumos de fácil transporte. Otras variantes de la lixiviación se introdujeron poco después: la de Gurlt, en 1851, la de Ziervogel, en 1857 y la de Von Patera, en 1858. Un requisito de todos estos métodos de lixiviación era haber obtenido una cloruración de la plata perfecta, para lo que se necesitaba una excelente molienda y un preciso horno de cloruración. La recuperación de la plata se podía estimar en un 85 por ciento.

Lo paradójico de esta historia es, sin embargo, que en el año 1849 no sólo se inventó este nuevo beneficio, sino que también se realizó el hallazgo de las minas de mercurio de Nuevo Almadén, en California, que abarató sensiblemente el precio del mercurio. De ahí que a lo largo de la segunda mitad del siglo pasado el método de la amalgamación no desapareciera, sino que incluso continuara su perfeccionamiento.

Alrededor de 1860, época en que Raimondi recorrió los principales asientos mineros del país, predominaba largamente el sistema de beneficio de patio, 0 «en crudo» (es decir, sin previa cocción). Sin embargo, cuando los minerales eran muy ricos, o el mercurio llegaba a precios demasiado elevados, se echaba mano 
también de la fundición ${ }^{28}$. En la década de 1830 aparecieron hornos modernos de fundición, como el introducido por Rudecindo Garrido en Hualgayoc en 1836 ${ }^{29}$; anteriormente se habían usado únicamente los primitivos hornos de huayra.

Por otra parte existían algunos establecimientos donde se venía usando el método de Freyberg o el «americano». La introducción de estos últimos debía ser más o menos reciente, por cuanto Mariano de Rivero, otro activo viajero y además Director Nacional de Minería hacia 1826-1828, no los menciona en sus escritos de esos años.

La amalgamación de patio era el método de beneficio casi exclusivo en Cerro de Pasco, principal plaza minera en los mediados de la centuria, pero podía hallársele en cualquier campamento minero: San Juan de Lucanas, San Mateo, Chicla, Hualgayoc. El procedimiento se desarrollaba a lo largo de diez fases sucesivas, a saber:

1. Molienda; realizada en un ingenio de piedra movido por fuerza hidráulica. Las piedras debían reemplazarse cada seis meses aproximadamente y significaban un gasto importante, tanto en su tallado, cuanto en su transporte. La molienda podía ser al seco o «en sutil» (con agua, para que el viento no se lleve el mineral en polvo).

2. Repaso en el circo; el mineral molido era trasladado en mantas por los operarios al patio circular de piedra, donde se añadía agua y sal y se mezclaba con caballos. Los caballos eran otro costo importante, porque su alimentación era muy cara por la escasez de forraje en las punas y morían con mucha frecuencia ${ }^{30}$. Raimondi estimó una mortandad del 20 por ciento anual en los

28 Davelouis ([13], p.14) se quejaba en 1862 que algunos mineros beneficiaban minerales «en crudo», cuando por su riqueza debía haberse optado por la fundición. El resultado era que en lugar de obtener 25 ó 30 marcos por cajón (un cajón tenía 60 quintales), apenas obtenían siete. Otros beneficiaban por fundición, pero con hornos muy toscos. Finalizaba diciendo: «Todos carecen de los más vulgares conocimientos y se dedican a la minería, sin saber ni la naturaleza ni la ley de sus metales. La grande mayoría usa de métodos empíricos y rutineros, ...».

29 Deustua [10], p.74. El cónsul inglés Charles Milner Ricketts reseñó acerca de Hualgayoc en 1826: «El único método adoptado en este distrito para la extracción de plata es el de amalgamación; la fundición es aún desconocida y podría ser introducida con ventaja.» Cfr., en DEUSTUA [10], id.

30 Du CHATENET escribió al respecto en 1879, que: «.. cada hacienda tiene que mantener para su servicio un número considerable de caballos, que llega a algunos centenares en una hacienda un poco importante. En los alrededores de Cerro no se crían caballos, y es preciso traerlos de las provincias ó departamentos vecinos. El precio corriente de cada uno puede estimarse en treinta soles. Pero la mortandad es muy grande y cada año se pierde una gran parte de ellos; por las malísimas condiciones higiénicas en que viven; están continuamente expuestos á los malos tratamientos de los indios; su trabajo es muy penoso en los circos, sobre todo en las tareas de ocho horas. Además, el pasto es muchas veces insuficiente; durante el invierno pueden encontrar alguna yerba en las pampas que son regadas con frecuencia por las lluvias; pero en el verano hay una sequedad extrema; las yerbas se hacen más y más escasas, los animales se enflaquecen, y muchísimos se mueren literalmente de hambre.» [18], p.91. 
caballos repasiles (Notas de viaje, t.III, p.40). Un circo solía tener capacidad para unos cuatro o cinco cajones, o unas doce toneladas de mineral.

3. Hormiguillo; se añadía magistral (pirita de hierro o cobre) y se mezclaba otra vez con los caballos.

4. Incorporo; luego de haber practicado la «puruña» (especie de ensaye en pequeña escala para saber qué cantidad de mercurio requería el mineral), se incorporaba mercurio a la masa y volvía a mezclarse.

5. Levanto; se añadía más azogue, levantando con palas la parte de abajo de la masa. También se le llamaba el «volteo». Se hacían más «repasos»: mezcla con caballos.

6. Llapa; si la puruña — que seguía haciéndose casi diariamente - indicaba que se necesita más azogue, se le añadía. Si la masa estaba en cambio muy «caliente», se incorporaba cieno o cal para enfriarla.

7. Matar el circo; último añadido de azogue para facilitar su reunión antes de levantar el circo.

8. Tina; se retira la masa del circo (para el efecto éste tenía una puerta, por donde también entraban los caballos) y se echa en unas tinas llenas de agua forradas de pellejos de animales para no perder amalgama. En las tinas los operarios agitaban con los pies la masa en el agua a fin de separar la amalgama del resto de tierra y escorias. De una tina, el agua iba pasando a otra, donde otros operarios repetían la labor para recuperar toda la amalgama formada. Luego se exprimían los pellejos, donde quedaba retenida algo de amalgama. Generalmente se usaba un juego de tres tinas.

9. Filtro; la amalgama («pella»), compuesta ya solamente de plata y mercurio, se colocaba en una manga cónica de tela para retirar el exceso de mercurio. Este caía por gravedad y era ayudado con golpes en la manga.

10. Postura; se colocaba la pella en un horno de «caperuza», donde se destilaba el mercurio aún contenido en ella con la ayuda de fuego manso. Resultaba entonces ya la plata «piña».

Toda la operación duraba dos o tres meses por lo general. Los conocedores de la metalurgia colonial de la plata apreciaron que la técnica era fundamentalmente la misma de antaño. Las mejoras consistían en que algunos ingenios eran ya movidos por turbinas hidráulicas, o en la mejor construcción de los hornos de caperuza, que permitían una mejor recuperación del mercurio. La recuperación de la plata contenida en el mineral podía estimarse en unos dos tercios o 65 por ciento.

Ciertos establecimientos habían introducido el método de barriles o de Freyberg, que Nordenflicht infructuosamente tratara de implantar a finales del siglo XVIII. Esta innovación fue propiciada, según puede deducirse de los apellidos de los administradores o conductores de las empresas, por inmigrantes europeos o norteamericanos, como Davelouis, Pflücker, Mac Lean o Williams, o por exper- 
tos peruanos enviados a Europa, como Mariano de Rivero. Raimondi menciona haciendas de beneficio con barriles en Castrovirreyna, Huarochirí y San Mateo, aun cuando esos establecimientos compartían el método europeo con la amalgamación de patio, o incluso la fundición, que a veces les daba mejor resultado. El tipo de mineral o los precios vigentes de los insumos dictaban el método a usar. Los barriles eran movidos por ruedas o turbinas hidráulicas, que también movían el ingenio y otros aparatos. El método de barriles se hallaba a mediados de siglo en una fase de experimentación, más que de uso en gran escala.

En la década de 1870 se abrirían dos importantes establecimientos de amalgamación mecánica: el de «Santa Erlinda», en Huánuco, de Gregorio Durand, que adoptó el sistema de barriles, y el de Morococha, de la casa Pflucker, que adoptó el de tinas de madera, muy poco usado en el país ${ }^{31}$.

El método de barriles suponía básicamente que el trabajo físico de los caballos o de los operarios en el circo, mezclando y agitando la masa, era realizado mecánicamente al girar los toneles por fuerza hidráulica. Los barriles solían tener paletas en su interior para un mejor efecto. Se ahorraba, pues, el gasto de los caballos y mucha mano de obra. Además el procedimiento no tomaba más de dos o tres días, en lugar de las varias semanas del de patio. Por otra parte la masa no perdía calor, como en los circos descubiertos; incluso podían calentarse los barriles realizando algunos arreglos en ellos, con un mejor resultado metalúrgico.

Con semejantes ventajas, no se entiende por qué la tecnología de Freyberg no alcanzó mayor escala en el país, sobre todo en el asiento de Cerro de Pasco. Raimondi sugirió que el tipo de minerales tan pobres en plata, con que se trabajaba, no permitía costear la «quema» en hornos necesaria para el método europeo o el de las tinas americanas. Du Chatenet mencionó también el alto costo del combustible y - junto con I. Bueno, otro ingeniero de minas-: «.. la tenacidad de los mineros de no abandonar los procedimientos antiguos de beneficio.» ${ }^{32}$.

El otro procedimiento era la fundición. Se usaba todo tipo de hornos; desde las pequeñas «huayras» indígenas, hasta hornos de reverbero que podían cargar unos quince quintales y alcanzaban grandes dimensiones. En 1860 Davelouis levantó en Chilete (Cajamarca) un horno de reverbero y otro de copelación para su propietario, el Sr. Barrantes. Todos se fabricaban con piedras refractarias. Raimondi encontró muy difundida la fundición en el asiento de Yauli, en la sierra central. El encarecimiento del azogue en las décadas previas impulsó el uso de la fundición ${ }^{33}$. Mencionó también Raimondi el caso de una señora, que «rescataba» minerales de los indios para fundirlos en su horno (id. p. 56). Parece que se trata-

31 JIMÉNEZ [3], p.50.

32 BMIC, tomo XI, Lima, 1894, p.95.

33 «Los habitantes de Yauli, principalmente los Mendizábal, manifiestan destreza en esta clase de beneficio; y se puede decir que han sido los primeros en introducirlo a Cerro de Pasco, en la época en que el azogue era muy caro, valiendo más de 200 pesos el quintal.» (RAIMONDI, [5] Notas de viaje, t.III, p. 58-59). 
ba de un caso frecuente. Los indios, dado el sistema de remuneración imperante, reunían minerales muy ricos, que ya podían beneficiarlos en pequeños hornos de huayra, o venderlos al propietario de un establecimiento de fundición.

El combustible utilizado era la taquia, estiércol de las llamas y ovejas. Aunque Mariano de Rivero lo juzgó de «poca fuerza», Raimondi opinó que su fuego manso era el más adecuado, porque si se usara carbón de piedra, las piedras de que estaba hecho el horno no resistirían tanto calor. Cuando debido al costo del mercurio, los mineros se «pasaban» a la fundición, la taquia llegaba a escasear, estimulando este tipo de ganadería. El naturalista italiano calculó que mil carneros depositaban en una sola noche de treinta a cuarenta costales de taquia (p. 61).

El procedimiento de fundición era harto sencillo: cargábase el mineral en estado «chancado» (molienda gruesa, hecha a veces con combas de mano), mezclado con algunas materias «fundentes» (escorias o almatarga). Previamente el horno había sido ya calentado. El mineral se iba cargando en varias etapas y la escoria ya fundida iba siendo filtrada por una abertura, hasta que al final quedaba el plomo fundido listo para la «copelación». Las ganancias podían ser muy altas, siendo los costos más elevados los de combustible y operarios. La plata obtenida no llegaba, sin embargo, a tener el grado de pureza que la de amalgamación.

Los ingenieros Du Chatenet y Delsol atestiguaron en Cerro de Pasco y la sierra de La Libertad, respectivamente, la vigencia de los métodos de amalgamación en 1879 y 1880 . En La Libertad se procedía con el sistema de Freyberg, mientras en Cerro de Pasco se proseguía con el método de patio. Du Chatenet vertió gruesas críticas al mismo: «Por su naturaleza misma, el método de circos lleva consigo inconvenientes gravísimos, que consisten principalmente en la lentitud de la operación, la pérdida de azogue y la pérdida de plata, relativamente á los otros sistemas empleados, ...» (p. 94). «... se puede decir con seguridad, que por el procedimiento de los circos, los mineros del Cerro no alcanzan á sacar de sus metales ni los dos tercios de su ley, lo que produce en minerales tan pobres una pérdida enorme.» (p. 95). Pero se mostró muy cauto ante la posibilidad de una rápida sustitución: si quería adoptarse la fundición, aparecía el problema de un combustible «demasiado caro»; igual si quería pasarse a los métodos de cloruración, en los que era necesario conseguir la calcinación de los minerales. La solución sería activar las minas de carbón, implantando vías férreas, pero esa ya era una tarea mayor (p. 96). «En la actualidad —concluía—, creo que todos los esfuerzos deben tender á conseguir una amalgamación más rápida y completa; pero sobre este punto es dudoso cual procedimiento deba preferirse, barriles como para la amalgamación sajoniense, ó tinas verticales, ó la amalgamación americana.» (p. 96). Más que la rapidez del beneficio, observó que habría que cuidar la economía del minero.

Du Chatenet realizó un cuidadoso estimado de los costos de la minería argentífera usando el método de patio en Cerro de Pasco, concluyendo en este cuadro para un circo de cuatro cajones:

\section{R. I., $1999, \mathrm{n}^{\circ} 216$}




\section{CUADRO 4}

Descomposición de costos de la producción de plata en Cerro de Pasco para un circo de cuatro cajones, 1879

\begin{tabular}{lcc}
\hline & Soles & $\%$ \\
\hline Extracción de los minerales & 48.00 & 17.8 \\
Fletes & 49.60 & 18.2 \\
Molienda & 60.00 & 22.2 \\
Beneficio & 85.30 & 31.6 \\
Interés de los capitales invertidos & 27.50 & 10.2 \\
\hline Total & 270.40 & 100.0 \\
\hline
\end{tabular}

Si consideramos que los capitales invertidos lo estaban sobre todo en las instalaciones de la hacienda de beneficio, podemos ver que más del $40 \%$ del costo de producción reposaba en el método de beneficio. De otra parte, llama la atención que el solo traslado de los minerales de las «canchas» de las bocaminas hasta los ingenios (generalmente a unos pocos kilómetros de distancia), es decir, los «fletes», represente un costo mayor que el mineral extraído, pero así era. Con semejante estructura de costos, no resulta extraño que fuera en el beneficio donde se concentraran los esfuerzos de transformación en el futuro.

\section{LA INTRODUCCION DE LA LIXIVIACION Y LA FUNDICION MODERNA}

Poco antes de la guerra con Chile sucedieron dos hechos decisivos para la minería, pero cuyos efectos recién se apreciarían tiempo después: la fundación de la Escuela de Ingenieros, en 1876, y la Ley de 1877. Para el funcionamiento de la Escuela llegó al país un conjunto de ingenieros de minas europeos que casi de inmediato comenzó a propagar en sucesivos viajes de estudio, los nuevos métodos de beneficio y trabajo minero. Aunque varios de ellos se quejaran del caracter tradicionalista de los mineros, lo cierto es que muchos llegaron a complementar sus salarios (seguramente menguados después del desastre de la guerra), asesorando a importantes empresarios de minas. La ley de 1877, por su parte, facilitó la delimitación de las pertenencias y promovió la inversión extranjera en la minería.

De otro lado, después de la Paz de Ancón (1883) los capitales del país habían visto desaparecer aquellos renglones especulativos que antes fueran su destino y pudieron volver los ojos al sector minero. A esto se sumó que en virtud del Contrato Grace (1889) los ferrocarriles fueron rehabilitados por la Peruvian Corporation y comenzó la prolongación de sus líneas. 
Aparecieron entonces las grandes «oficinas metalúrgicas», que no solamente beneficiaban minerales de sus propias minas, sino que además compraban minerales de pequeños mineros, carentes de los medios para invertir en plantas de beneficio. Ya en 1879 la Compañía Minera del Ferrocarril de la Oroya y Cerro de Pasco había mandado a fabricar en Estados Unidos un gigantesco molino, pero cuya implantación se vió frustrada en 1880 por la guerra ${ }^{34}$. En 1889 se abrió, sin embargo, la oficina Backus y Johnston en Casapalca, cuyas instalaciones «.. no pueden compararse á ninguna otra, en cuanto á perfección, en toda la América meridional (...) que nada envidia á las oficinas de fundición de los Estados Unidos» ${ }^{35}$. Por los mismos años se abrirían las oficinas de Huauracaca y Humanrauca, cerca de Cerro de Pasco, conducidas por empresarios nacionales, y también similares en Ancash y Hualgayoc. Se trataba de oficinas de fundición equipadas con grandes trituradoras Blake, que usaban hornos de manga, de camisa de agua («water jacket») o grandes hornos de reverbero.

El ferrocarril llegó a La Oroya en 1893, atravesando por las regiones mineras de Casapalca y Morococha, y tardó todavía una década más en alcanzar Cerro de Pasco, pero ya desde 1889 las expectativas (y en consecuencia las inversiones) de los mineros se adelantaron a las líneas férreas. El ferrocarril trajo dos consecuencias; de un lado provocó, igual que en Bolivia, la tendencia a exportar minerales, antes que plata refinada; pero de otro, resolvió el problema del combustible, puesto que podía ahora importarse, como en efecto se importó, el coke inglés, así como aprovecharse las minas de carbón del país. Las modernas oficinas usaron también la taquia, cuando la energía de este combustible era bastante, pero su uso fue desapareciendo en el beneficio a gran escala ${ }^{36}$. El ferrocarril servía tanto para estimular la exportación de materiales aún no plenamente refinados, como para promover la refinación «in situ», al abaratar la provisión de los insumos necesarios. Una tendencia se oponía y hacía equilibrio a la otra, pero al fin las dos impulsaron las grandes oficinas metalúrgicas. Puesto que para poder exportar minerales, éstos debían ser muy ricos de ley, o pasar por un proceso de concentración en las oficinas metalúrgicas, que aumentase su proporción de plata o cobre. La concentración operaba sobre todo por fundición, obteniéndose «matas» o «ejes» con ley de 120 a 700 marcos por cajón. Cuando la compañía del ferrocarril elevaba sus tarifas, se prefería beneficiar la plata localmente; si, al contrario, ellas bajaban, la tendencia era a exportar minerales antes que plata refinada ${ }^{37}$. El costo del transporte se convirtió en el factor decisivo para la decisión de beneficiar localmente o producir concentrados.

\footnotetext{
34 BMIC, a. VII, 1891, p.54

35 Ibidem, a. IX, 1893.

36 Ibidem, a. II, 1891, p.9.

37 Ibidem, a. VIII, 1892.
} 
Los métodos de beneficio hicieron progresos. Todavía en los inicios de la década de 1890 podría encontrarse muy difundida la amalgamación de patio en Cerro de Pasco, pero con una mejor preparación previa de los minerales, que redujo en importante proporción el consumo de mercurio. La mejora en la preparación consistió en que antes de la operación de amalgamación en los circos, practicábase una calcinación clorurante en hornos de reverbero (una técnica tomada del método de lixiviación) ${ }^{38}$.

El cuadro 5 muestra que a lo largo del siglo XIX pudo conseguirse una importante reducción en los rubros de mercurio (azogue), jornales y caballos repasiles. Después de la guerra con Chile también puede apreciarse una disminución en el costo de la molienda y el transporte (bajas y fletes). Fueron estas transformaciones las que permitieron la subsistencia del método de amalgamación hasta casi el final del siglo XIX.

En Puno era popular el método de barriles, usando la oficina Maravillas grandes toneles que alcanzaban a contener cada uno un cajón de mineral ${ }^{39}$; la oficina La Victoria, en Yauli, operaba con la amalgamación en tinas, siendo capaz de tratar hasta cien toneladas diarias; «es sin duda el primer establecimiento metalúrgico del Perú, ...» proclamó el entusiasta observador; en la oficina Tuctu, del ingeniero Schefer, se utilizaba el «método de Freyberg modificado» ${ }^{40}$.

Estas oficinas fueron diseñadas con gran cuidado. La de «La Victoria» asombró al profesor Venturo (de la Escuela de Ingenieros) por el arte con el que estaban dispuestos los aparatos en diferentes niveles, de modo que los materiales pasaban de una fase a otra aprovechando la gravedad y sin usar casi mano de obra; «todo se hace como automático», anotó ${ }^{41}$. Rosemary Thorp y Geoffrey Bertram, en su conocido trabajo sobre historia económica del Perú resaltan el hecho que buena parte de la inversión y dirección de este proceso modernizador en la minería estuvo en manos de empresarios nacionales ${ }^{42}$. En algunos casos se trataba ciertamente de inmigrantes (de naciones europeas y los Estados Unidos), pero que habrían constituido localmente sus empresas, pero tampoco debe desdeñarse la importancia que ya desde estos años tuvo la inversión extranjera. En el caso de los empresarios «nacionales» (aunque se trate de inmigrantes en varios casos), aún es tema por investigar la manera como financiaron la modernización del proceso metalúrgico ${ }^{43}$.

\footnotetext{
38 Ibidem, a.X, 1894.

39 «Maravillas era propiedad de una empresa británica». BMIC, a.X, 1894. PosTH, «Estado actual de la minería en el departamento de Puno.», p. 54.

40 BMIC, a.IX, 1893. Torrico Mesa, «Excursión a Huarochirí y Yauli», p. 48.

41 Ibidem, a.X, 1894. P.C. Venturo, Excursión a Huarochirí y Yauli.

42 Rosemary THORP y Geoffrey BERTRAM, Perú 1890-1977. Opciones y políticas en una economía abierta, Lima, 1985, pp. 106-117.

43 En su sólido trabajo Banqueros en conflicto, Lima, Universidad del Pacífico, 1989, Alfonso QUIROZ advierte que la nueva banca surgida después de la guerra del Pacífico, no invirtió en mine-
} 


\section{CUADRO 5}

Descomposición de los costos de beneficio por amalgamación de patio, de un cajón en Cerro de Pasco, siglo XIX

\begin{tabular}{lcrrr}
\hline Rubro & 1828 & 1878 & 1879 & 1891 \\
\hline Extracción del mineral & $6 \mathrm{p}$ & 20.00 & 12.00 & 12.00 \\
Bajas y fletes & $5 \mathrm{p} 1.5$ & 12.00 & 12.40 & 7.00 \\
Molienda & $12 \mathrm{p}$ & 20.00 & 15.00 & 10.00 \\
Sal & $7 \mathrm{p}$ & 6.00 & 6.25 & 4.90 \\
Azogue & $9 \mathrm{p}$ & 8.00 & 6.00 & 5.50 \\
Combustible & $1 \mathrm{p}$ & 2.12 & 0.25 & 0.40 \\
Jornales y caballos & $12 \mathrm{p} 4$ & 9.25 & 9.75 & 5.95 \\
Otros (reactivos, etc.) & - & 1.75 & 0.25 & 0.40 \\
\hline Total & $52 \mathrm{p} 5.5$ & 79.12 & 65.90 & 55.15 \\
\hline
\end{tabular}

Notas: La columna de 1828 está dada en pesos de ocho reales. Las demás, en soles, cuya equivalencia es igual a la del peso, pero divididos en cien centavos. En 1828 el dato de la extracción del mineral contempla «saca sin bombas» (para el desagüe), porque con ellas el costo aumentaría. Todos los casos, contemplan cajones con una ley de 5 marcos, salvo el de 1828 , donde la fuente indica 8 marcos, pero sin aclarar si son netos o brutos. Debe tomarse en cuenta que en 1878 y 1879 el uso del papel billete infló las cifras y que si deflatáramos los valores, el costo del beneficio de 1891 sería menor que el de 1828 (disponemos de un deflator en Gootenberg, «Carneros y chuñu, ... En HAHR 1990. Durham).

Fuentes: Para 1828, Rivero, ob. cit. Para 1878, Fuentes, Estadística de las Minas...; para 1879, Du Chatenet, ob. cit. Para 1891, I. Bueno, «Asiento del Cerro de Pasco». En BMIC, a.VII, 1891.

Pero entre todos los métodos, el más novedoso y que rápidamente se abrió paso fue el de la lixiviación. Comenta Jiménez en su reseña histórica ya citada, que fue el químico Pedro Hugón el primero en montar el procedimiento en el asiento de Araqueda, en Cajabamba, basándose en el método Augustín, en el año 1848; «el mismo que habría funcionado «intermitentemente desde 1848 hasta 1854 , con resultados deficientes que obligaron a paralizarla, volviéndose a la amalgamación en circos.» (pp. 49-50) ${ }^{44}$. Ese mismo año (1848), Héctor Davelouis y otros colegas, habían publicado en Lima un pequeño libro dando cuenta de un procedimiento para el beneficio de la plata «por vía húmeda sin azogue» ${ }^{45}$.

ría en toda esta época; pero también destaca la presencia de capitales especulativos entre 1888 y 1891, pp. 38-39.

44 Esta fecha sería anterior a la invención en Alemania. Pero no se dispone de más referencias ni el asunto se ha investigado como merece.

45 La referencia completa, ofrecida por José TORIBIO POLO en su Reseña histórica de la minería en el Perú Lima, 1911, p. 65, es la siguiente: Elementos de beneficios de metales de plata por vía húmeda sin azogue, por los señores Héctor Davelouis, profesor de Química y Metalurgia, 
Probablemente se trató del mismo procedimiento implantado por Hugón (presuntamente también francés) en Cajabamba. El abaratamiento del azogue tras el descubrimiento de las minas de California postergaron por varias décadas estos intentos técnicos en la metalurgia, que habrían sido por lo menos paralelos a los hallazgos de la metalurgia europea y norteamericana.

El año 1890 oficinas de lixiviación se inauguraron casi simultáneamente en varios lugares. En la Negociación Santa Bárbara, en el pueblo de Yauli, y en Hualgayoc, en el establecimiento de Pilancones, se puso en práctica el método Pattera. En los años siguientes se abrieron más oficinas de este tipo en Cajatambo, Ancash y Cerro de Pasco. Al informar sobre el asiento de Cerro de Pasco en 1893, el corresponsal informó que «varias de las antiguas oficinas de amalgamación se han transformado en oficinas de lixiviación, ... ${ }^{46}$. En 1898 se contaban ya nueve plantas de lixiviación en Hualgayoc y por lo menos trece en todo el país ${ }^{47}$. Las oficinas de lixiviación no exportaban, sin embargo, plata, sino sulfuros de plata, una suerte de mineral muy concentrado.

La Escuela de Ingenieros, en boca de su director, Eduardo de Habich, se ufanaba en 1895 del éxito de la lixiviación, como uno de sus más importantes logros:

«Como ejemplo en el orden de propagación de un procedimiento nuevo, citaremos el de beneficio de minerales de plata por lixiviación, tan esparcido hoy en toda la República. Desde 1885 se han efectuado estudios prácticos en la Escuela, relativos á ese proceder y se publicaron muy importantes artículos al respecto en el Boletín, desde su origen, en 1885, siendo el éxito definitivo de todos estos estudios, informes y publicaciones, la propagación del método tan apreciado actualmente en el país» ${ }^{48}$.

La Escuela hizo campaña desde 1891 por la implantación del método Russell, empleado entonces en Estados Unidos y México y que no exigía, como las demás variantes de la lixiviación, una perfecta cloruración, publicando en efecto varios artículos en su Boletín.

En uno de los boletines, correspondiente al año 1892, apareció una confrontación de los resultados económicos de la lixiviación frente a la amalgamación, en Cerro de Pasco. El beneficio de cinco cajones por el método de patio resultaba en un costo de 265.75 soles, mientras el de la lixiviación por el procedimiento Russell, en 258.38 soles. Magra distancia como para abandonar lo viejo conocido. Pero la gran diferencia residía en que la amalgamación sólo conseguía sacar

Melchor Charon, profesor de Metalurgia ensayador que fue de la Compañía Inglesa de Minas del Río de la Plata, Henrique Erdman, oficial de minería del Rey de Prusia, Emeterio Villamil, minero y metalurgista, fundadores y socios de la Compañía de Vía Húmeda en la República del Perú. Lima, Imprenta del Correo Peruano, 1848, en octavo. No he podido encontrar este ejemplar en Lima.

46 Ismael Bueno, «Asiento del Cerro de Pasco», BMIC, a.X, 1894., p.3.

47 Fermín Málaga Santolalla, «El asiento mineral de Hualgayoc», Boletín del Cuerpo de Ingenieros de Minas. Lima, 1904 y El Economista, 9 de enero de 1897.

48 BMIC, a.XI, 1895. Eduardo de Habich, p. 27. 
el $50 \%$ de la plata (según el boletín), mientras el nuevo método obtenía el $80 \%$; es decir, 30 marcos contra 47.5 marcos. Añadía el articulista otra serie de ventajas: mejores condiciones de seguridad para los operarios y un giro más rápido del capital, puesto que el minero tendría la piña diariamente ${ }^{49}$.

La estadística minera de 1903 - la primera aparecida después de la de Fuentes, y mucho más completa además - señaló el tipo de «productos» en que estuvo contenida la plata producida ese año:

\section{CUADRO 6}

Producción de plata según productos en que estuvo contenida, 1903

\begin{tabular}{lcc}
\hline & kilos & Porciento \\
\hline Barras de plata & 19,651 & 11.5 \\
Barras de plomo & 2,682 & 1.6 \\
Matas de cobre & 45,661 & 26.7 \\
Sulfuros de lixiviación & 31,890 & 18.7 \\
Minerales y concentrados & 70,722 & 41.4 \\
Otros productos & 198 & 0.1 \\
\hline Total & 170,804 & 100.0 \\
\hline
\end{tabular}

Fuente: Extracto estadístico del Perú, 1920, p.77.

Los productos más importantes fueron los derivados de los procedimientos de fundición (matas de cobre y concentrados). No puede establecerse la magnitud con precisión, puesto que no sabemos cuántos de los 70,722 kilos fueron minerales brutos y cuántos concentrados. Sigue en jerarquía la lixiviación, con un 19 por ciento del total. El cuadro tampoco permite saber cuánto dependía todavía de la amalgamación, puesto que las barras de plata (producto de este método) también podrían haber sido obtenidas por los otros procedimientos. Pero en cualquier caso es claro que la amalgamación ya estaba en franca retirada, puesto que en ningún caso habría superado el 12 por ciento del total de la producción.

Otro dato del avance de los beneficios por fundición y lixiviación nos lo da un cuadro de oficinas metalúrgicas de 1920. De 79 oficinas existentes en el país, el mayor número: 27, eran de lixiviación; 23, de fundición de matas de cobre (un

49 Ibidem, a.VIII, 1892, pp. 37-38. Exageraba el articulista, puesto que la amalgamación sacaba corrientemente unos dos tercios de la plata contenida en los minerales, con lo que la diferencia sería de 40 frente a 47.5 marcos.

R. I., $1999, \mathrm{n}^{\circ} 216$ 
concentrado del que se obtenía plata y cobre) y fundición plomosa (exclusivamente para plata) y sólo 4 , de amalgamación, además de 2 de cianuración de plata ${ }^{50}$.

Los métodos de beneficio dominantes desde mediados de la década de 1890 - la fundición y la lixiviación - prescindieron del uso de caballos y más tarde, asimismo, de la taquia (recurriendo como combustible al carbón y el petróleo). Si bien se ganó en cuanto a productividad de la mano de obra (en 1905 el número de operarios había recuperado ya un nivel muy similar al de finales del siglo XVIII, llegando a 9651, según el Extracto Estadístico de 1920, por lo que también hubo aumento en la fuerza laboral), perdiose el enlace del sector minero con la ganadería, de larga data en las economías regionales hispanoamericanas. Ello se vio reforzado con el uso del ferrocarril, que desplazó a mulas y llamas del trajín de minerales, sal, taquia y demás sustancias. La minería se modernizaba, pero a costa de aislarse de la economía del entorno, ya que los nuevos insumos (productos químicos, combustibles y maquinaria de acero) eran en buena parte, importados, y de volverse aún más primaria, en el sentido que dejaba de exportar metal refinado para exportar sobre todo concentrados.

\section{CONCLUSIONES}

Desde la independencia, salvo la coyuntura del efímero boom que trajo la conclusión del socavón de Quiulacocha, c.1840, la minería de la plata atravesó una situación de estancamiento y moderada decadencia, de la que no se recuperaría hasta después de la guerra con Chile. La imagen de «fracaso» fue en todo caso aumentada por el contraste con las expectativas de crecimiento y grandes ganancias que se crearon con la independencia. Entre 1821 y 1889 se produjo en promedio anual un 89 por ciento de lo que había sido la producción de plata en la década 1801-1810; de modo que la evaluación hecha por los observadores contemporáneos, que retratan un panorama de total decadencia, ha pecado de catastrofismo. Fue el impresionante despegue de la producción de plata en México, Rusia y los Estados Unidos lo que hizo perder peso a la producción nacional, desplazándola a una posición ya marginal en el contexto mundial.

El estancamiento tuvo entre sus causas el escaso progreso de la metalurgia. Agobiados por la falta de capital, la dificultad para conseguir trabajadores cualificados y la incertidumbre en las comunicaciones y la vida política, los mineros del siglo XIX se dedicaron más a tratar de perfeccionar el método de patio ya conocido, que a procurar un cambio técnico profundo. Algunas innovaciones se realizaron en nuevos asientos, como San Mateo, o en viejos, como Castrovirreyna, lo que prueba que la nueva tecnología estuvo disponible en el Perú, pero ella

\footnotetext{
50 Extracto estadístico del Perú, 1920. p.79.
} 
no alcanzó a modificar la técnica imperante en el más importante asiento: el Cerro de Pasco.

La imagen de un total estancamiento técnico en este asiento ha sido, sin embargo, creada sobre todo por observadores europeos, como Raimondi, Tschudi o los recién llegados profesores de la Escuela de Ingenieros, o peruanos europeizados, como Rivero de Ustariz. En Cerro de Pasco el viejo procedimiento de patio fue readecuado hasta el punto de lograr reducir y transformar la estructura de costos del beneficio ${ }^{51}$. Aunque el principio químico y el nombre del método eran los mismos, el método imperante en 1890 no era el mismo que se practicara durante la época colonial. Es importante valorar esta transformación, oscurecida luego por el triunfo de la lixiviación y la fundición, dado el hecho que el Perú disponía de yacimientos de mercurio, como el de Huancavelica, que debían ser potenciados.

El cambio radical en el beneficio, hacia nuevos métodos de amalgamación, como el de Freyberg, o a la lixiviación, requería grandes inversiones de capital. Si bien éstos se hallaban disponibles en el país gracias a la bonanza del guano desde 1850 , no drenaron hacia la minería, debido, por un lado, a la posibilidad de fáciles y seguras ganancias en otros rubros, y de otro, a la defectuosa legislación que gobernaba el sector. En consecuencia el capital era un recurso escaso en la minería y los mineros hicieron un uso finalmente eficiente del mismo. Cuando los dos factores que alejaron el capital del sector minero mejoraron, la transformación técnica operó con relativa rapidez. Pero ello coincidió con el surgimiento de una corriente de inversiones extranjeras en toda América Latina, de modo que el impulso para el cambio técnico tuvo un fuerte componente externo. El hecho que el Perú hubiera sido durante doscientos cincuenta años un gran productor de mercurio, y en cambio escaso en material energético, probablemente explique por qué hasta tan tarde se insistió en los métodos de amalgamación y no en los alternativos.

Después de firmada la Paz de Ancón y retirado el ejército de ocupación (1884), en medio de todavía severas restricciones económicas en el sector público, presentáronse tres alternativas de cambio técnico: 1 . el perfeccionamiento de la amalgamación, adoptando los métodos de barriles, o de tinas con «fondos»; 2. la fundición en modernos hornos de manga o camisa de agua; y 3 . la lixiviación. En realidad, a partir de la instauración del ferrocarril existía una alternativa más, que al final explica la dirección del cambio técnico: la exportación de los mine-

51 Muy ponderado fue en este sentido el parecer del médico y viajero alemán Ernest Middendorf, quien reconoció que no sólo el difícil acceso a los centros de producción era una de las barreras que debía superar la minería, sino que el tratamiento de los minerales era «una difícil tarea, que, según su naturaleza y su composición química tiene que ser resuelta en cada caso.» «Se necesita gran paciencia y experimentos en cada lugar para obtener favorables resultados; no bastan, por regla general, los conocimientos adquiridos en Europa y aplicados por fundidores extranjeros, ya que los minerales de yacimientos peruanos son de naturaleza diferente a los que ellos están acostumbrados, y exigen un tratamiento distinto, cuyo conocimiento sólo se adquiere con la práctica.» (El Perú, 1880).

R. I., $1999, \mathrm{n}^{\circ} 216$ 
rales, y no del metal refinado. Pero para poder exportar minerales concentrados (aún a pesar del ferrocarril, los centros mineros quedaban aislados y el transporte seguía siendo un costo importante, sobre todo porque las líneas ferroviarias para la minería no se concluyeron hasta más o menos el inicio de la primera guerra mundial) debía instaurarse métodos de fundición, de los que se obtenían matas y ejes «de cobre», o de lixiviación, de los que resultaba sulfuro de plata. Finalmente estos métodos, fundición y lixiviación, fueron los que reemplazaron el método de amalgamación de patio en la década de 1890. Una vez más los barriles fracasaron, como en 1790. Aquella vez por demasiado nuevos; ésta, por demasiado viejos

La Escuela de Ingenieros hizo campaña por la lixiviación, publicando artículos y realizando diversas excursiones con profesores y alumnos a los principales asientos mineros. En el Perú de entonces un reducido pero activo grupo profesional, podía alcanzar grande capacidad de transformación. Mientras las empresas extranjeras, que comenzaron a instalarse en el país desde 1885 aproximadamente, parecían inclinarse por la fundición. ¿Existía debajo de esta lucha de técnicas un enfrentamiento de otro tipo? ¿Por ejemplo, la defensa nacionalista de la Escuela del proyecto que el país exportase plata refinada y no mineral concentrado solamente?

$\mathrm{Al}$ comienzo la lixiviación pareció llevar la delantera, pero en los primeros años del siglo XX, una vez resuelto, mediante la extensión de los ferrocarriles, el aprovisionamiento de combustible, la fundición se impuso. En 1913, de las 299 toneladas de plata producidas, sólo 8 (menos del $3 \%$ ) «pudieron» haber sido por amalgamación; 51 fueron el resultado de la lixiviación (17\%), mientras el resto $(80 \%)$ respondió a la fundición. Para ello fue decisivo el hecho que la plata comenzó a producirse más como un subproducto del cobre, que por sí misma ${ }^{52}$. El cambio técnico llevó a records inéditos de producción, pero la integración del sector minero con la economía doméstica a través de la dotación de insumos, inaugurada con el método de la amalgamación en 1575, debilotose fuertemente (todo no se puede tener). El proyecto de lixiviación de la Escuela de Ingenieros procuraba mantener todavía una industria local de insumos a través de la elaboración en cada asiento de los ingredientes requeridos, pero el abaratamiento del combustible conseguido a través del ferrocarril terminó imponiendo la fundición ya en los primeros años del siglo XX.

After being in use for three centuries in the Peruvian silver mining, tha amalgamation with mercury method was replaced in 1890's. This took place when the main world producers had been using a different method for over half a century. This delay was due to several factors: there was a mercury mine in Peru which, though not in use, was always expected to be reactivated; there was no cash availability for a main technical change; and the legislation that had been in force for a

52 Extracto Estadístico del Perú 1920. Lima, 1922.

R. I., $1999, \mathrm{n}^{\circ} 216$ 
long period did not foster large-scale mining. When some of these conditions changed after 1885, there was a battle over technical change fought by the Engineer School of Mines (Escuela de Ingenieros) on one part, and foreign enterprises, which both defended different methods. The latter won the battle when the railways were finished in early $20^{\text {th }}$ Century. The winning proposal was more efficient in technical terms but had less redistributive effects at the regional and national economic level.

R. I., 1999, n. $^{\circ} 216$ 